\title{
CECÍlIA MEIRELES E O CANTO DO ROMANCEIRO EM MEMÓRIA AOS INCONFIDENTES MINEIROS
}

\author{
Ana Paula Prado \\ Manoel Francisco Guaranha
}

\section{RESUMO}

Neste trabalho, pretende-se analisar o poema Romance XLIX ou de Cláudio Manuel da Costa" do livro Romanceiro da Inconfidência (1953), romance dedicado a um dos principais nomes da Inconfidência Mineira, Cláudio Manuel da Costa (1729-1789). Pretende-se destacar as relações interdiscursivas entre história e literatura por meio do diálogo entre as diversas vozes que o enunciador póe em conflito no poema.

PALAVRAS CHAVE: Cecília Meireles, poesia brasileira, análise do discurso.

\section{A dramaticidade do romanceiro pela Inconfidência Mineira}

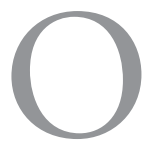

livro Romanceiro da Inconfidência, de Cecília Meireles, foi publicado em 1953, com base em pesquisas realizadas, durante a estada da escritora na cidade mineira de Ouro Preto, sobre um dos mais importantes momentos da história brasileira: o movimento pela independência do Brasil denominado Inconfidência Mineira, ocorrido no ano de 1789.

O título da obra sugere tratar-se de uma coleção de romances, aqui compreendida como um gênero essencialmente poético que se encontra na confluência entre a narrativa e o drama cuja origem se funde à própria formação das línguas neolatinas, bem como absorve aspectos da oralidade: 
O falar romance passou a designar, no curso da Idade Média, as línguas dos povos sob domínio romano, em lenta, mas inexorável autonomização. Com o tempo, a expressão passou a indicar a linguagem do povo em contraste com a dos eruditos. Mais adiante, acabou rotulando as composiçóes literárias de cunho popular, folclórico. E, como estas fossem de caráter imaginativo e fantasista, a expressão prestava-se para nomear narrativas em prosa e verso. [...] A mesma classificação se atribuía aos poemas narrativos em torno das proezas dos cavaleiros andantes, ou de temas amorosos, épicos, moralistas, satíricos, etc. (MOISÉS, 2008, p. 157).

Não vamos aqui considerar o sentido moderno que o termo romance adquiriu a partir do século XVIII e ao longo do século XIX, quando passou a designar as narrativas literárias voltadas ao público burguês, já que essa acepção não categoriza nosso corpus. De qualquer modo, tal qual seu homônimo contemporâneo, o romance medieval é bastante variado. Sob essa rubrica são reunidos textos de espectro bastante amplos o que nos leva a destacar algumas características específicas destas composições que fundamentam nossa análise.

Nesse sentido, um aspecto importante é o caráter dialogal desses textos essencialmente líricos. Conceituamos diálogo, para este trabalho, como uma fala em que há a interação entre indivíduos, um colóquio ou uma conversa e também um solilóquio, que caracteriza a conversa do sujeito consigo mesmo. Esse diálogo confere ao gênero certo tom dramático, já que permite ao enunciatário sentir-se diante de um enunciador que se expressa, muitas vezes, como se tivesse estado próximo aos acontecimentos servindo-se dos discursos direto e indireto para apresentar as falas das personagens.

O texto do Romanceiro da Inconfidência selecionado para a análise é narrativo. Nele, o enunciador registra várias versóes do fato histórico, a prisão e morte de Cláudio Manuel da Costa (1729-1789), personagem de dimensão histórica, que esteve envolvido na Inconfidência Mineira; e de dimensão literária, cultor da poesia lírica, da poesia épica e também do gênero romance.

Para facilitar a compreensão da análise, transcreveremos a seguir o "Romance XLIX ou de Cláudio Manuel Da Costa”: 
1. "Que fugisse, que fugisse...

2. - bem lhe dissera o embuçado!

3. que não tardava a ser preso,

4. que já estava condenado,

5. que, os papéis, queimasse-os todos...”

6. Vede agora o resultado:

7. Mais do que preso está morto,

8. E com o pescoço metido

9. num nó de atilho encarnado.

10. - Isso é o que conta o vizinho

11. Que ouviu falar o soldado.

12. Mas do corpo ninguém sabe:

13. Anda escondido ou enterrado?

14. Dizem que o viram ferido,

15. ferido, e não sufocado:

16. de borco em poça de sangue,

17. por um punhal traspassado.

18. - Dizem que não foi atilho

19. nem punhal atravessado,

20. mas veneno que lhe deram,

21. na comida misturado.

22. E que chegaram doutores,

23. e deixaram declarado

24. que o morto não se matara,

25. mas que fora assassinado.

26. E que o Visconde dissera:

27. "Dai-me outro certificado,

28. que aquele ficou perdido,

29. por um tinteiro entornado!"

30. e quem vai saber agora

31. o que se terá passado? 
32. - Talvez o morto fosse outro,

33. em seu lugar colocado.

34. A sombra da noite escura

35. encobre muito pecado.

36. Talvez pelo subterrâneo

37. fosse ao Palácio levado...

38. Era homem de muitas luzes,

39. pelo povo respeitado;

40. Secretário do Governo,

41. que vivia em grande estado:

42. casa de trinta aposentos,

43. muito dinheiro emprestado,

44. e do velho João Fernandes,

45. dono do Serro, afilhado!

46. - Não creio que fosse morto

47. por um atilho encarnado,

48. nem por veneno trazido,

49. nem por punhal enterrado.

50. Nem creio que houvesse dito

51. o que lhe fora imputado.

52. Sempre há um malvado que escreva

53. o que dite outro malvado,

54. e por baixo ponha o nome

55. que se quer ver acusado...

56. Entre esta porta e esta ponte,

57. fica o mistério parado.

58. Aqui, Glauceste Satúrnio,

59. morto, ou vivo disfarçado,

60. deixou de existir no mundo,

61. em fábula arrebatado,

62. como árcade ultramarino

63. em mil amores enleado.

64. (MEIRELES, 1997, p. 109) 
No "Romance XLIX ou de Cláudio Manuel da Costa" confrontam-se várias vozes em um discurso permeado por outros discursos, o que dá ao texto um tom de murmúrio, de vozes indistintas e distantes, cujo efeito de sentido reconstrói o mistério que cerca o fim trágico do inconfidente, encontrado morto em sua cela na prisão.

O suicídio do poeta, causa oficial da morte de Cláudio Manuel, é fato refutado por alguns historiadores. Essa refutação está reconstruída também pelo enunciador ao longo do romance, notadamente pela estrutura dialogal do texto, em que são apresentadas as várias versões da morte do poeta: enforcamento (versos 8 e 9), traspassamento por punhal (versos 13 a 16), envenenamento (versos 19 e 20); ou, ainda, versão de que o inconfidente teria escapado da prisão disfarçado (versos 31 e 32).

No romance, o enunciador recria o processo de construção do mito em torno do inconfidente servindo-se: a) dos verbos dicendi que marcam o diálogo: "dissera o entrevistado" (verso 2), "é o que conta o vizinho" (verso 9), "Dizem" (versos 13 e 18); "o Visconde dissera" (verso 25); b) do registro de suas impressóes: "Não creio" (verso 46), "nem creio" (verso 50).

Grande parte do efeito dramático é proveniente, ainda, da métrica e do ritmo do poema narrativo, que possui 63 versos distribuídos em sete estrofes, sendo que a maioria deles possui sete sílabas poéticas (redondilho maior), retomando o estilo do cancioneiro popular. Segundo Norma Goldstein:

O verso de sete sílabas, heptassílabo ou redondilha maior, é o mais simples, do ponto de vista das leis métricas. Basta que a última sílaba seja acentuada, os demais acentos podem cair em qualquer outra sílaba. Talvez por isso ele seja o verso predominante nas quadrinhas e cançôes populares. Verso tradicional em língua portuguesa, já era frequente nas cantigas medievais (GOLDSTEIN, 1987, p. 27).

No romance em questão, a simplicidade do heptassílabo nos remete à oralidade e à espontaneidade, bem como sugere a incorporação da trajetória de Cláudio Manuel no universo simples do povo.

Os recursos fonéticos reforçam o tom de murmúrio que comentamos anteriormente. A repetição anafórica do "que" na primeira estrofe, por exemplo, 
contribui para isso. Ao longo de todo o poema, sempre nos versos pares, tem-se a presença de rimas consoantes alternadas [-ado], constituídas pela terminação dos verbos no particípio passado, que cria certo efeito de eco, som indistinto, rumor, como a simular as diferentes versóes sobre a morte do poeta que ecoam ao longo dos tempos.

Nessa recorrência sonora, destaca-se, ainda, o efeito da repetição da vogal posterior /o/ em posição de fim de verso, evocando a sensação de obscuridade sonora e remetendo o leitor aos sentimentos inerentes à tristeza, solidáo e morte. O fechamento sonoro sugere, ainda, o caráter de mistério que cerca a morte do poeta árcade. Nesse sentido, apoiamo-nos nas observaçóes de Martins (2003, p. 32) quando afirma que: "[...palavras mais fortemente motivadas ajustam-se à expressão do sofrimento, e algumas delas ganham relevo pela posição em fim de versos]". Ao longo do poema, ao apropriar-se de diferentes vozes que veiculam tanto o discurso histórico oficial quanto as muitas versóes populares sobre a morte do inconfidente, o enunciador as redimensiona, às vezes questionando as informaçóes de diversas origens, como aquelas apresentadas na terceira estrofe, iniciada com o verbo no presente do indicativo cujo sujeito da oração é, além de indeterminado: "Dizem [...]".

$\mathrm{Na}$ quarta estrofe, o enunciador apresenta a fala de "doutores" que teriam "declarado" que o inconfidente náo se matara, mas teria sido assassinado e, depois, que o Visconde de Barbacena, personagem histórico, governador da Capitania àquela época, ter lhes-ia solicitado que fizessem outro certificado sobre a causa mortis do poeta uma vez que o primeiro fora perdido acidentalmente (versos 26 a 31). A justificativa de perda acidental do documento, por causa de um tinteiro entornado, é questionada pelo enunciador que, ao refletir sobre como se chegar à verdade sem o documento, em certo sentido desmascara como criminosa a destruição do papel.

Esse efeito de sentido, de pôr em confronto diferentes vozes, amplia-se na quinta estrofe, em que o advérbio dubitativo "talvez" abre o primeiro e o quinto versos, apontando para a possibilidade, inclusive, de ser outro corpo, não o de Cláudio Manuel, o encontrado na cela, já que este era Secretário do Governo e afilhado de João Fernandes ${ }^{1}$, portanto homem influente e não

1 O contratador João Fernandes de Oliveira (1720-1799) mudou-se para o arraial de Tijuco (Diamantina - Minas Gerais - Brasil) para cumprir a função de contratador de diamantes, funçâo que lhe garantia a exploração de diamantes no Brasil. Por sua influência na socie- 
sujeito aos rigores da lei como estavam os mais humildes.

Este entrelaçamento de vozes constrói as mútuas relaçóes dialógicas entre as vozes do enunciador, do discurso histórico e as de outros sujeitos que são apresentados como personagens.

$\mathrm{Na}$ sexta estrofe, tem-se a tomada de posição do enunciador diante do tema "Não creio", quando reiteradamente nega todas as versóes antes apresentadas unindo-as por meio da conjunçâo "nem", bem como nega as supostas declaraçóes de Cláudio Manuel$^{2}$. A estrofe termina com reticências, prenúncio do mistério que será instaurado na sétima estrofe, que se separa das outras formalmente, inclusive, posto que está impressa em itálico, conforme edição usada neste trabalho (MEIRELES, 1997, p. 109).

Nela, o sujeito materializa no texto o mistério por meio de vários procedimentos linguísticos. Primeiro, o enunciador parte de espaços concretos, marcados pelo dêitico, os pronomes demonstrativos "esta" e "aqui", que se referem ao espaço entre a porta e a ponte. A primeira, provavelmente a porta da Casa dos Contos, onde o protagonista esteve preso e, conforme a história oficial, onde foi encontrado morto; e a segunda, provável referência à Ponte Antonio Dias em Vila Rica (atual Ouro Preto - MG). Depois, refere-se a Cláudio Manuel pelo seu pseudônimo poético, Glauceste Satúrnio, que “deixou de existir no mundo, / em fábula arrebatado", como se ele tivesse saído da vida para entrar, ingressar, definitivamente, na ficção como "árcade ultramarino”, que é, aliás como se notabilizou a figura de Cláudio Manuel, essencialmente um poeta árcade "em mil amores enleado", e não como o personagem histórico enleado no "atilho encarnado" dos versos iniciais, nem como aquele

dade diamantinense, tornou-se padrinho de mulatos, filhos bastardos, escravos e brancos, alimentando uma relação que lhe garantia respeito e aceitação social junto às diversas classes sociais. Assim (sem registro histórico), teria apadrinhado a Cláudio Manuel da Costa, como a tantos outros, embora, na ocasiáo da morte de Cláudio Manuel, já estivesse morando em Portugal há 19 anos. (fonte: site Cidades Históricas Brasileiras, disponível em: http://www. cidadeshistoricas.art.br/hac/bio_jfo_p.php).

2 As supostas declaraçóes de Cláudio Manuel da Costa teriam sido proferidas contra Tomás Antonio Gonzaga no Auto da Devassa (ordem criada no século XVII pela Rainha para procurar documentos ou obras de arte para provar que o indivíduo investigado era um inconfidente). Segundo Lopes (1997, p. 130), “[...] estas declaraçóes foram julgadas injurídicas. [...] não houve testemunhas durante o interrogatório. Não constam nos Autos da Devassa”. Teriam sido atribuídas a Cláudio Manuel da Costa, numa tentativa de "isca” para que outros interrogados caíssem em contradição em seus depoimentos. 
que se teria acovardado à hora da morte, como consta nas declaraçóes do Auto da Devassa, fato não comprovado historicamente.

De qualquer modo, neste ponto, o romance de Cecília Meireles reafirma seu objetivo enunciativo, qual seja transportar a figura que elege como tema do domínio da história para o campo simbólico do literário, ou seja, deixou de existir no mundo arrebatado em fábula.

\section{Consideraçóes finais}

Cecília Meireles conseguiu, ao longo do poema, compor o cenário dos acontecimentos, utilizando-se de recursos sonoros, como rimas e versos, ao estilo do cancioneiro popular e do gênero romance. Esse ritmo e essa sonoridade, bem como a escolha do gênero, a forma como apresenta as diferentes vozes que dão conta dos acontecimentos reconstroem o mistério e instauram-no como ingrediente necessário à poesia, remetendo-nos àquilo que é essencial na figura do personagem título do romance: a literatura pautada pelo tema amoroso.

Desse modo, tanto as versôes oficiais como as oficiosas sobre os fatos relativos à vida do autor ganham um contorno de ruído em relação à poesia dele, que é o que persiste na última estrofe. Sob esta perspectiva, o caráter metalinguístico do texto torna-se uma reflexão sobre a literatura do período, já que, como árcade ultramarino, o poeta mineiro Cláudio Manuel da Costa explorou intensamente os grandes veios da poesia do tempo: o anseio de liberdade, igualdade e fraternidade e a neoclássica inspiração árcade.

\section{Referências}

D'ANDRÉA, Carlos F. Cidades Históricas Brasileiras. Disponível em http:// www.cidadeshistoricas.art.br/hac/bio_jfo_p.php. Acesso em 25 de junho de 2013. GOLDSTEIN, Norma. Versos, Sons, Ritmos. 4. ed. São Paulo: Ática, 1987. IGLÉSIAS, Francisco. Inconfidência Mineira. Disponível em http://www.tiradentes.net/historia3.htm. Acesso em 21 de abril de 2013.

LOPES, Hélio. Letras de Minas e Outros Ensaios. São Paulo: Edusp, 1997. Disponível em e-book http://books.google.com.br/books?id=p--jHdG3PCUC\&pg=PA13 0\&lpg=PA130\&dq=declara $\% \mathrm{C} 3 \% \mathrm{~A} 7 \% \mathrm{C} 3 \% \mathrm{~A} 3 \mathrm{o}+\mathrm{de}+\mathrm{Cl} \% \mathrm{C} 3 \% \mathrm{~A} 1$ udio + Manuel $+\mathrm{d}$ 
a+Costa\&source=bl\&ots=R14TGLH_Qx\&sig=RVQC07uW95E3u56urFRBcbyu-lE\&hl=pt-BR\&sa=X\&ei=Rl_KUcOvNanj0QHUyYHoBw\&ved=0CEoQ6AEwBA \#v=onepage\&q=declara\%C3\%A7\%C3\%A3o\%20de\%20Cl\%C3\%A1 udio\%20Manuel\%20da\%20Costa\&f=false. Acesso em 26 de junho de 2013.

MARTINS, Nilce Sant'Anna. Introdução à Estilistica. São Paulo: Edusp, 2003. MEIRELES, Cecília. Romanceiro da Inconfidência. In: Poesia Completa. Volume 2. Rio de Janeiro: Nova Fronteira, 1997.

MOISÉS, Massaud. A Criação Literária - Prosa I - Fôrmas em prosa - O conto - A novela - O romance. 21. ed. São Paulo: Cultrix, 2008.

\title{
"CECÍLIA MEIRELES AND SINGING IN MEMORY OF BALLADS TO THE CONSPIRACY MINERS"
}

\begin{abstract}
In this work, we intend to analyze the poem: Romance XLIX or Cláudio Manuel da Costa "of the book 'Romanceiro da Inconfidência” (1953) , dedicated to romance one of the leading names in the Minas Conspiracy, Cláudio Manuel da Costa (1729-1789) . It is intended to highlight the interdiscursive relationship between history and literature through dialogue between different voices that the utterer puts conflict in the poem.
\end{abstract}

KEYWORDS: Cecília Meireles, Brazilian poetry, speech analysis.

Recebido em: 27/09/2014 Aprovado em: 25/02/2015 